Supporting Information for

\title{
Quantum-Mechanical Structure Optimization of Protein Crystals and Analysis of Interactions in Periodic Systems
}

Taiji Nakamura, ${ }^{a}$ Tomoko Yokaichiya, ${ }^{a, b}$ Dmitri G. Fedorov ${ }^{a, ~ *}$

${ }^{a}$ Research Center for Computational Design of Advanced Functional Materials (CD-FMat), National Institute of Advanced Industrial Science and Technology (AIST), Central 2, Umezono 1-1-1, Tsukuba, 305-8568, Japan.

b Current affiliation: Department of Chemical System Engineering, Graduate School of Engineering, the University of Tokyo, Hongo 7-3-1, Tokyo, 113-8656, Japan.

* Corresponding author 


\section{Extension of the partition analysis to treat periodic boundary conditions}

The extension of the original $\mathrm{PA}^{1}$ to treat periodic boundary conditions is rather simple. In PA, the total energy $E$ for a system divided into $M$ segments is computed as a sum of the values $E_{i}$ for segments $i$ and interactions $\Delta E_{i j}$ in $i, j$ pairs,

$E=\sum_{i=1}^{M} E_{i}+\sum_{i>j}^{M} \Delta E_{i j}$

With $\mathrm{PBC}$ all solvent is treated explicitly, and the interaction $\Delta E_{i j}$ is decomposed into the electrostatic (ES) and dispersion (DI) components,

$\Delta E_{i j}=\Delta E_{i j}^{\mathrm{ES}}+\Delta E_{i j}^{\mathrm{DI}}$

The PBC effects are hidden inside the energies appearing in eq S1, and the equation is applicable both with and without $\mathrm{PBC}$. Without PBC, ${ }^{1}$ for DFTB3 the contribution is computed for pairs of atoms $A$ and $B$, using their charges $Q$ as

$$
\begin{aligned}
& \Delta E_{i j}^{\mathrm{ES}}=\sum_{A \in i} \sum_{B \in j} \Delta E_{A B}^{\mathrm{ES}} \\
& \Delta E_{A B}^{\mathrm{ES}}=\gamma_{A B} Q_{A} Q_{B}+\frac{1}{3}\left(\Gamma_{A B} Q_{A}+\Gamma_{B A} Q_{B}\right) Q_{A} Q_{B} .
\end{aligned}
$$

Whereas for PBC one uses PBC-modified $\gamma$ and $\Gamma$-terms (denoted by a tilde), ${ }^{2}$

$$
\Delta E_{A B}^{\mathrm{ES}}=\tilde{\gamma}_{A B} Q_{A} Q_{B}+\frac{1}{3}\left(\widetilde{\Gamma}_{A B} Q_{A}+\widetilde{\Gamma}_{B A} Q_{B}\right) Q_{A} Q_{B}
$$

See Ref. 3 for a definition of $\gamma_{A B}$ and $\Gamma_{A B}$, and Ref. 2 for a definition of $\widetilde{\gamma}_{A B}$ and $\widetilde{\Gamma}_{A B}$. Likewise, $\Delta E_{i j}^{\mathrm{DI}}$ is calculated with $\mathrm{PBC}$ using PBC-summed inverse distances ${ }^{2}$ and $E_{i}$ is also calculated in a similar fashion by a trivial extension of the original formulation. 
One important comment should be made as to the interpretation of $\Delta E_{i j}$. By its definition, it includes a sum of the interaction of segment $i$ in the primary cell 0 and segment $j$ in all cells including 0 (the explicit summation is performed inside the $\tilde{\gamma}_{A B}$ and $\widetilde{\Gamma}_{A B}$ terms). Therefore, $\mathrm{PBC}$ has an accumulated effect of a summation to infinity (over cells for $j$ with the fixed cell for $i$ ) in $\Delta E_{i j}$ which may result in an enhancement of interactions.

It often happens that a segment $j$ in a replicated image cell has a strong interaction with a segment $i$ in the primary cell, so that in visualizing interactions one should take care to consider multiple images of the periodic cell (see Fig. 1 in Ref. 2), not just the primary cell.

Also, it should be noted that in the calculation of $R_{i j}$ (the distance between segments $i$ and $j$ ), one segment is put in the primary cell 0 , and the other is placed in each replicated cell including 0 . Among all such cell pairs, the minimum distance between atoms in $i$ and atoms in $j$ is found. 
Table S1. Crystallographic Data for Protein Crystals.

\begin{tabular}{|c|c|c|c|c|c|c|c|c|c|c|c|c|}
\hline $\begin{array}{c}\text { PDB } \\
\text { ID }\end{array}$ & $\begin{array}{l}\text { Space } \\
\text { group }\end{array}$ & $\begin{array}{l}\text { Residue/ } \\
\text { protein }\end{array}$ & $\begin{array}{l}\text { Charge/ } \\
\text { protein }\end{array}$ & $\begin{array}{l}\text { Protein/ } \\
\text { cell } \\
\text { calc }\end{array}$ & $\begin{array}{c}\text { Molecules/ } \\
\text { cell }^{\mathrm{a}} \\
\text { calc }\end{array}$ & $\begin{array}{l}\text { Added H/ } \\
\text { protein } \\
\text { calc }\end{array}$ & $\begin{array}{c}\text { Density } \\
\mathrm{g} / \mathrm{cm}^{3}, \\
\text { expt }\end{array}$ & $\begin{array}{l}\text { Density } \\
\mathrm{g} / \mathrm{cm}^{3}, \\
\text { calc }\end{array}$ & $\begin{array}{c}\mathrm{V}_{\mathrm{S}}, \\
\%, \\
\text { expt }\end{array}$ & $\begin{array}{c}\text { Buffer } \\
\text { pH } \\
\text { expt }\end{array}$ & $\begin{array}{c}\text { Temp. } \\
\mathrm{K}, \\
\text { expt }\end{array}$ & $\begin{array}{c}\text { Resolution } \\
\AA \\
\text { expt }\end{array}$ \\
\hline $1 \mathrm{ETL}^{4}$ & P $12{ }_{1} 1$ & 13 & -1 & 2 & $\begin{array}{l}27 \mathrm{H}_{2} \mathrm{O} \\
+2 \mathrm{H}_{3} \mathrm{O}^{+}\end{array}$ & 0 & 1.350 & 1.352 & 17.80 & & & 0.89 \\
\hline $5 O Q Z^{5}$ & P $122_{1} 1$ & 18 & -1 & 2 & $\begin{array}{l}35 \mathrm{H}_{2} \mathrm{O} \\
+2 \mathrm{H}_{3} \mathrm{O}^{+}\end{array}$ & 0 & & 1.333 & 15.19 & 4.6 & 100 & 0.81 \\
\hline $3 \mathrm{Q} 8 \mathrm{~J}^{6}$ & P 1 & 37 & 0 & 1 & $\begin{array}{l}11 \\
\text { Methanol } \\
+10 \mathrm{H}_{2} \mathrm{O}\end{array}$ & 0 & 1.207 & 1.205 & 21.32 & & 90 & 0.87 \\
\hline $1 \mathrm{CBN}^{7}$ & P $122_{1} 1$ & 46 & 0 & 2 & $\begin{array}{l}182 \mathrm{H}_{2} \mathrm{O} \\
+2 \text { Ethanol }\end{array}$ & 2 & & 1.264 & 30.90 & & 130 & 0.83 \\
\hline $2 \mathrm{VB} 1^{8}$ & P 1 & 129 & 10 & 1 & $\begin{array}{l}231 \mathrm{H}_{2} \mathrm{O} \\
+9 \mathrm{NO}_{3}^{-} \\
+3 \mathrm{Ethandiol}^{-} \\
+1 \mathrm{AcO}^{-}\end{array}$ & 5 & & 1.278 & 26.90 & 4.7 & 100 & 0.65 \\
\hline
\end{tabular}

${ }^{\mathrm{a}} \mathrm{H}_{3} \mathrm{O}^{+}$were manually placed near an anionic residue before adding solvent. 


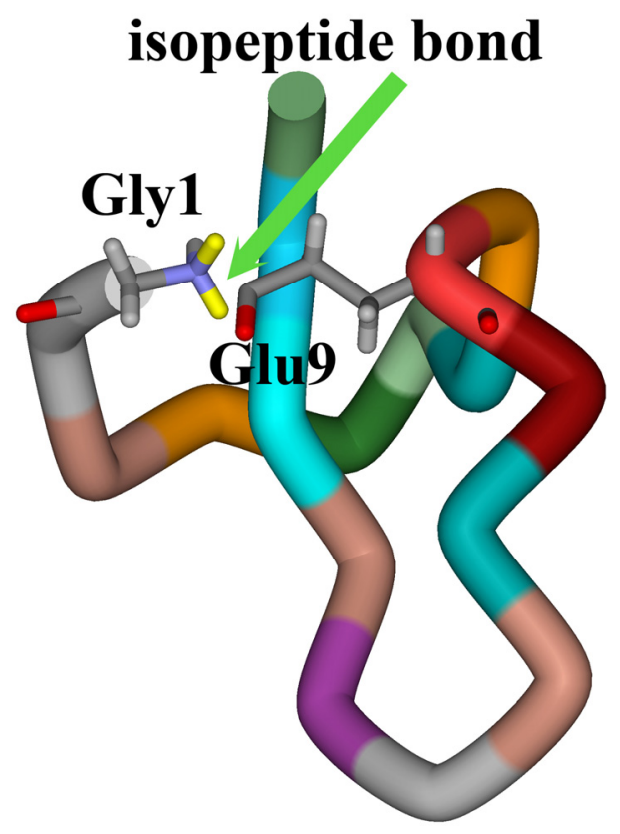

Fig. S1. The isopeptide bond in 5OQZ having two extraneous hydrogens (yellow) in the experimental structure.

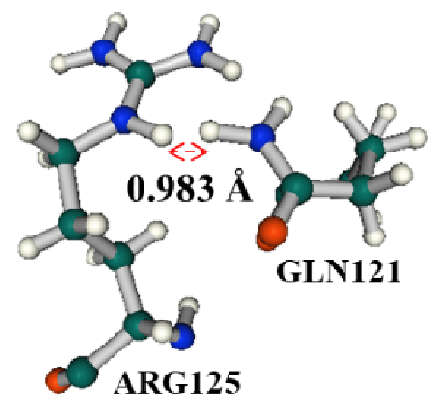

Experimental structure

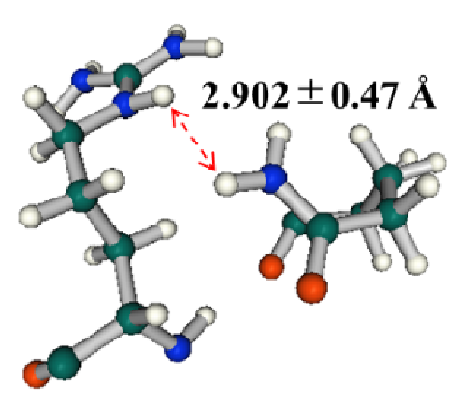

Optimized structure

Fig. S2. The most problematic close contact in the experimental structure of 2VB1 resolved by an FMO-DFTB optimization. 
References

(1) Fedorov, D. G. Partition Analysis for Density-Functional Tight-Binding. J. Phys. Chem. A 2020, 124, 10346-10358.

(2) Nishimoto, Y.; Fedorov, D. G. The Fragment Molecular Orbital Method Combined with Density-Functional Tight-Binding and Periodic Boundary Conditions. J. Chem. Phys. 2021, 154, 111102.

(3) Nishimoto, Y.; Fedorov, D. G.; Irle, S. Third-Order Density-Functional Tight-Binding Combined with the Fragment Molecular Orbital Method. Chem. Phys. Lett. 2015, 636, 90-96.

(4) Sato, T.; Ozaki, H.; Hata, Y.; Kitagawa, Y.; Katsube, Y.; Shimonishi, Y. Structural Characteristics for Biological Activity of Heat-Stable Enterotoxin Produced by Enterotoxigenic Escherichia Coli: X-Ray Crystallography of Weakly Toxic and Nontoxic Analogs. Biochemistry 1994, 33, 8641-8650.

(5) Fouque, K. J. D.; Lavanant, H.; Zirah, S.; Hegemann, J. D.; Fage, C.D.; Marahiel, M. A.; Rebuffat, S.; Afonso, C. General Rules of Fragmentation Evidencing Lasso Structures in CID and ETD. Analyst 2018, 143, 1157-1170.

(6) Li, H.; Bowling, J. J.; Fronczek, F. R.; Hong, J.; Jabba, S. V.; Murray, T. F.; Ha, N.-C.; Hamann, M. T.; Junga, J. H. Asteropsin A: An Unusual Cystine-Crosslinked Peptide from Porifera Enhances Neuronal $\mathrm{Ca}^{2+}$ Influx. Biochim. Biophys. Acta 2013, 1830, 2591-2599.

(7) Teeter, M. M.; Roe, S. M.; Heo, N. H. Atomic Resolution (0.83 Å) Crystal Structure of the Hydrophobic Protein Crambin at 130 K. J. Mol. Biol. 1993, 230, 292-311. 
(8) Wang, J.; Dauter, M.; Alkire, R.; Joachimiak, A.; Dauter, Z. Triclinic Lysozyme at $0.65 \AA$ Resolution. Acta Crystallogr. D Biol. Crystallogr. 2007, 63, 1254-1268. 